\title{
IMAGINARIOS DEL PUERTO LAMAR DESDE 1825 A 1877
}

\author{
IMAGINARIES OF PORT OF LAMAR FROM 1825 TO 1877
}

\author{
Javiera Letelier Cosmelli y Victoria Castro Rojas ${ }^{2,3}$
}

\begin{abstract}
En este trabajo se analiza la construcción de los imaginarios del Puerto Lamar en Cobija, emplazado actualmente en la región de Antofagasta, desde su creación en 1825 hasta 1870, previo a la Guerra del Pacífico. El Puerto Lamar fue un proyecto político que se configuró junto con la creación de la república boliviana a inicios del siglo XIX, con el objetivo de incentivar el desarrollo del capitalismo a través de la conexión ultramarina de Bolivia con el resto del mundo. De este modo, en Cobija se generó una nueva realidad local en donde se distinguió un notable incremento de población, la transformación del paisaje y consecuentemente, donde se conformaron diversos imaginarios en tensión sobre este enclave en el desierto de Atacama.

Palabras claves: imaginarios, paisaje, Desierto de Atacama, Puerto Lamar, Cobija.
\end{abstract}

This paper presents an analysis of the construction of imaginaries of Port of Lamar in Cobija, currently located in the Antofagasta region, from its creation in 1825 until the years before the War of the Pacific. The Port of Lamar was a political project of the recently created Republic of Bolivia at the beginning of the XIX century. It aimed at promoting the development of capitalism through the overseas connection of Bolivia with the rest of the world. In this context, a new local reality was created in Cobija, in which it is possible to identify an increase in population, the transformation of landscape, and, consequently, a configuration of diverse imaginaries within this enclave in the Atacama Desert.

Key words: Imaginaries, landscape, Atacama Desert, Port of Lamar, Cobija.

En la costa de Desierto de Atacama, a unos pocos kilómetros al sur de Tocopilla, aún se divisan los cimientos derruidos de las casas (Figura 1), la iglesia y las calles de Cobija, ahora una ciudad en ruinas. Sus restos evocan el esfuerzo de hombres y mujeres que durante el siglo XIX convirtieron la costa desértica de Atacama en un lugar lleno de vida. En la actualidad, una jauría de perros habita la zona alta de la otrora ciudad y en los esbozos de las antiguas casas emergen habitaciones de material liviano (Escobar 2015), que aprovechan parte de los muros de adobe que aún resisten los embates de un maremoto, el tiempo y el abandono.

La historia precolombina de Cobija y de esta región costera en general, da cuenta de una ocupación continua por parte de poblaciones cazadoras recolectoras marítimas, reconocida por lo menos desde los 7.000 años AC (Castro et al. 2016). Desde entonces, nunca dejó de estar presente este quehacer que la caracteriza hasta la actualidad. Durante los primeros años de la conquista hay tempranas noticias de este lugar tanto en el siglo XVI (Bibar 1966 [1558]) como en el siglo XVII, con excelentes descripciones de Lizárraga (1987 [1594-1608]) sobre las actividades de pesca realizadas allí por los indígenas de la zona.

En términos geográficos esta zona comprende parte de la costa arreica definida por la ausencia de cursos de agua permanentes que desemboquen en el mar. A su vez, la costa se define por planicies costeras interrumpidas al sur de la región por la Cordillera de la Costa. La ciudad que anida la bahía, fue fundada en

\footnotetext{
${ }^{1}$ Universidad Austral de Chile, Puerto Montt, Chile. javieraletelier@gmail.com

${ }^{2}$ Departamento de Antropología, Facultad de Ciencias Sociales, Universidad Alberto Hurtado, Santiago, Chile. macastrr@uahurtado.cl

${ }^{3}$ Departamento de Antropología, Facultad de Ciencias Sociales, Universidad de Chile, Santiago, Chile.
}

Recibido: abril 2017. Aceptado: octubre 2018.

http://dx.doi.org/10.4067/S0717-73562018005002201. Publicado en línea: 14-noviembre-2018. 


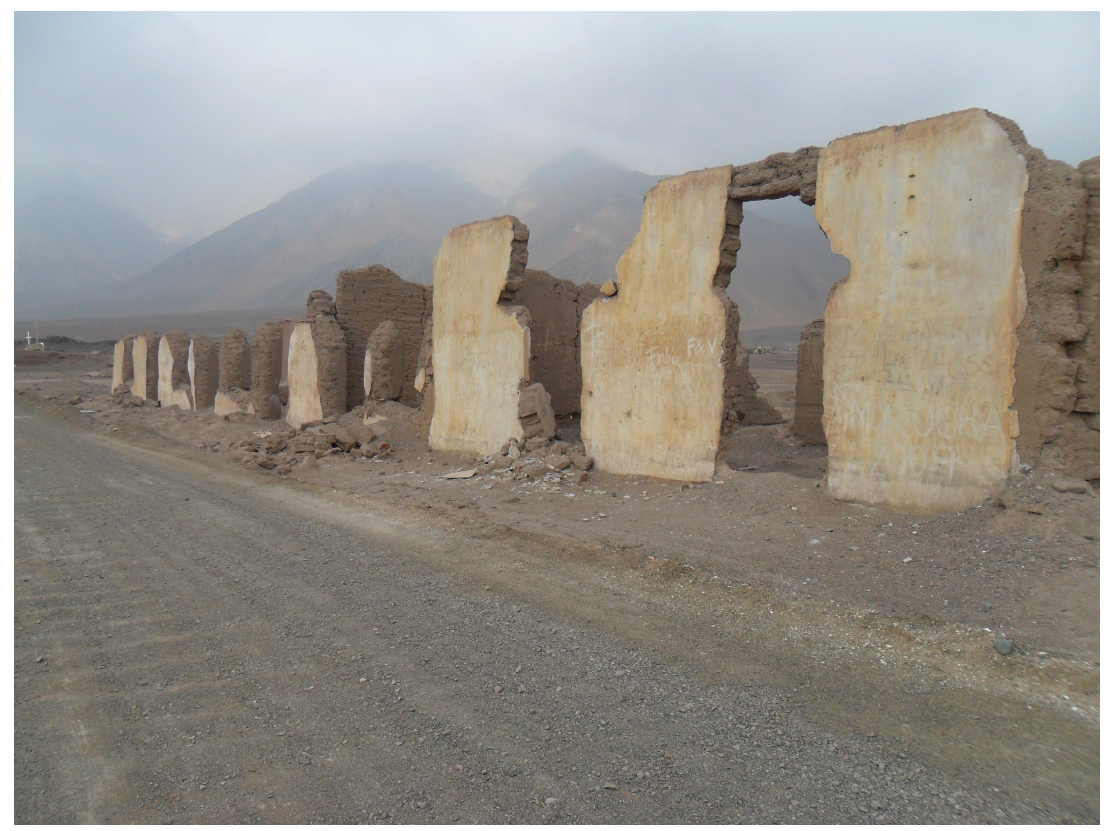

Figura 1. Ruinas actuales del Puerto Lamar.

Current ruins of Port of Lamar.

1587 bajo el nombre de Santa María Magdalena de Cobija, para servir de refugio a los marinos en un tramo de la costa particularmente inhóspito (Fifer 1976).

Durante la administración colonial, el "Puerto de Santa Magdalena de Cobija" fue residencia de españoles e indios vinculados a la pesca, recolección marina y al tráfico desde y hacia Potosí (Fifer 1976) y se constituyó como un puerto alternativo frecuentado por corsarios, piratas y contrabandistas que burlaban los intereses comerciales de la Corona, que debido a su lejanía, dificultad de acceso y escasez de agua, no se encontraba controlada por las autoridades administrativas (Bittmann 1980). Muy temprano también, en el siglo XVII, Cobija fue dotado de una iglesia para la evangelización de los indígenas que mantuvo protagonismo durante prácticamente toda la época Colonial (Castro 2009).

La creación del Puerto Lamar en el asentamiento colonial de Santa Magdalena de Cobija se enraizó en el nacimiento del Estado boliviano, sustentado en una política económica minera extractiva con orientación externa (Mitre 1981). Para ello, fue necesario el impulso de un puerto propio que permitiera que la nueva república se conectara con el resto del mundo (Letelier 2016). La existencia de un puerto para el Alto Perú, posteriormente Bolivia, fue parte del imaginario de la nueva nación desde la independencia en 1825. De hecho, la Asamblea General de diputados de las provincias del Alto Perú discutió el tema de la conectividad y, en consecuencia, del puerto como argumento fundamental para llevar a cabo un proyecto exitoso de independencia (Cajías 1975). De este modo, en diciembre de 1825 se oficializó la creación del Puerto Lamar en Cobija. No obstante, su habilitación formal comenzó dos años más tarde, debido a la situación de aislamiento de este asentamiento en relación al resto de Bolivia y de la falta de agua dulce, recurso básico de subsistencia (Cajías 1975, 2007; Téllez y Silva 2012). Pese a lo anterior, la condición de Cobija como puerto de Bolivia permitió que este se estableciera, desde sus inicios, en un enclave multiétnico en donde convivieron diversos grupos que transformaron y percibieron este espacio desde su propio prisma (Letelier y Castro 2015).

Desde fines de la década de $1860 \mathrm{y}$, posteriormente, durante la década de 1870 , se observa un vuelco irreversible en la historia del puerto, debido a una serie de desastres naturales y antrópicos. Destaca la epidemia de fiebre amarilla en 1869 , cuyo resultado con decenas de fallecidos fueron devastadores (Galaz-Mandakovic y Owen 2014). A lo anterior se suma el terremoto del 13 de agosto de 1868 con epicentro en Arica y, finalmente, el terremoto y maremoto del 8 de mayo de 1877, que arrasó completamente con el puerto (Arce 1997 [1930]). El paisaje relicto que hoy puede observarse en Cobija comprende estas ruinas de adobe, de alturas aún imponentes de las que queda uno que otro muro, en cuya superficie los efectos de los maremotos son evidentes. Nunca se reedificó y la desolación se siente hasta hoy, no obstante, la belleza escénica del lugar (Castro et al. 2012) (Figura 2). Toda esta situación, se sumó a la crisis del puerto 
en desmedro del crecimiento de asentamientos vecinos como Antofagasta, junto con el tenso clima producto de las disputas territoriales y de recursos con Chile, previo a la guerra del Pacífico (Cavieres 2007).

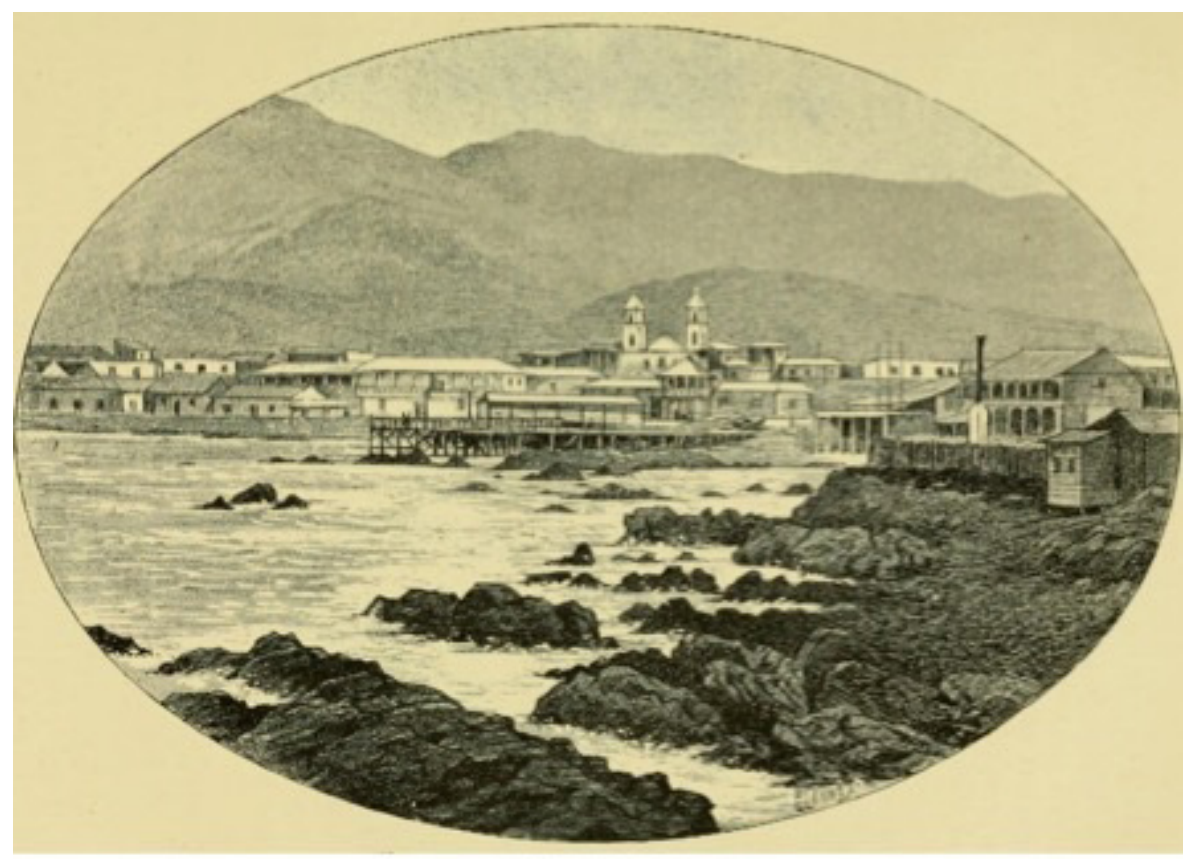

Figura 2. Vista general del Puerto Lamar (Bresson 1886).

General view of Port of Lamar (Bresson 1886).

\section{Imaginarios, Espacios y Paisajes de Cobija}

Los imaginarios dependen de la relación entre el ser humano y su contexto (Castoriadis 1997) y se constituyen "como matrices de sentidos que se sitúan en la difusa frontera de lo real y lo imaginado, constituyendo expresiones simbólicas que suponen un ánimo de visualizar lo invisible" (Márquez 2007:80) ${ }^{1}$. Bajo este entendido, se toma la idea de los imaginarios geográficos, como una perspectiva de base fenomenológica que busca dar protagonismo a los sujetos y a la imaginación geográfica,

...que puesta en práctica para aproximarnos al pasado, permitiría, por un lado, entender las nociones de espacio y tiempo que convivían y entraban en conflicto en una determinada época y, por el otro, comprender las luchas por la apropiación espacial que se derivaban del choque entre estas nociones (Zusman 2013:52).

En tal sentido, el espacio se constituye en paisaje entendiendo por este la "síntesis de las relaciones de las diferentes percepciones que el hombre tiene de los hechos concretos" (Gallastegui y Galea 2009). El paisaje nos revela no solo aspectos físicos, sino una dimensión simbólica que guarda directa relación con cómo el ser humano se apropia de este, apropiación que se enmarca en un horizonte de sentidos que son aprehendidos por las personas según su contexto (Claval 2012).

Así, en el Puerto Lamar ocurrieron transformaciones sociopolíticas, culturales y paisajísticas durante el siglo XIX (Lofstrom 1991), las que se sustentaron en el incentivo del capitalismo industrial a partir de la creación del estado boliviano. En este contexto, entendemos el capitalismo como un sistema social histórico (Wallerstein 2003), cuyo origen se remonta a la configuración del sistemamundo. Por ello se entiende que: "la globalización en curso es, en primer término, la culminación de un proceso que comenzó con la constitución de América y el del capitalismo colonial/ moderno y eurocentrado como un nuevo patrón de poder mundial" (Quijano 2000:201). De allí que se afirme que el primer horizonte colonial es paralelo a la formación de la América del siglo XVI (Quijano 2000). Este proceso es sintetizado por Quijano como la "colonialidad del poder" advirtiendo que este es el patrón de poder que domina, incluso en la 
actualidad, el que "pese a tener sus orígenes en el colonialismo ha probado ser más duradero y estable" (Quijano 2000:201).

Esta "colonialidad del poder" se observa a través del manejo económico y político de ciertos grupos sociales por sobre otros en el espacio de la Bolivia republicana e implicó una modificación de la estructura social, política y económica del puerto y, consecuentemente, de su espacio y la percepción de éste (Letelier y Castro 2016).

\section{Antecedentes Generales}

A fines de 1825 la necesidad de generar una vía de comunicación exclusiva del Alto Perú, impulsó la creación del puerto de Cobija. La elección del lugar estuvo a cargo del Mariscal Burdett O'Connor, militar de confianza de Sucre, quien definió que la rada de Cobija, prácticamente despoblada, poseía condiciones aptas para el desarrollo de un puerto (Cajías 1975; Letelier 2016; Letelier y Castro 2015).
Con el desarrollo de Lamar se generó una nueva dinámica cosmopolita en la zona, la que no estuvo exenta de problemas debido a los conflictos políticos, territoriales y económicos con los países vecinos (Figura 3). A partir de esta situación, se pueden identificar una serie de periodos que permiten analizar cómo ocurren y se transforman las relaciones sociopolíticas en el contexto local.

Existe un primer momento, desde 1825 a 1840 , desde la independencia de Bolivia hasta el inicio de la intensificación de la explotación del guano en Atacama. Durante este periodo, la necesidad de incentivar la minería en Potosí impulsó la construcción de rutas de comunicación, con el objeto de activar el tráfico arriero y la circulación desde el interior de la República hasta la costa. En esta escena, destaca la puesta en marcha del camino que unió la costa de Lamar con la ciudad de Potosí (Borie et al. 2016; Cajías 1975). Para la implementación del Puerto Lamar en 1827 se dictaron una serie de medidas cuyo objetivo principal

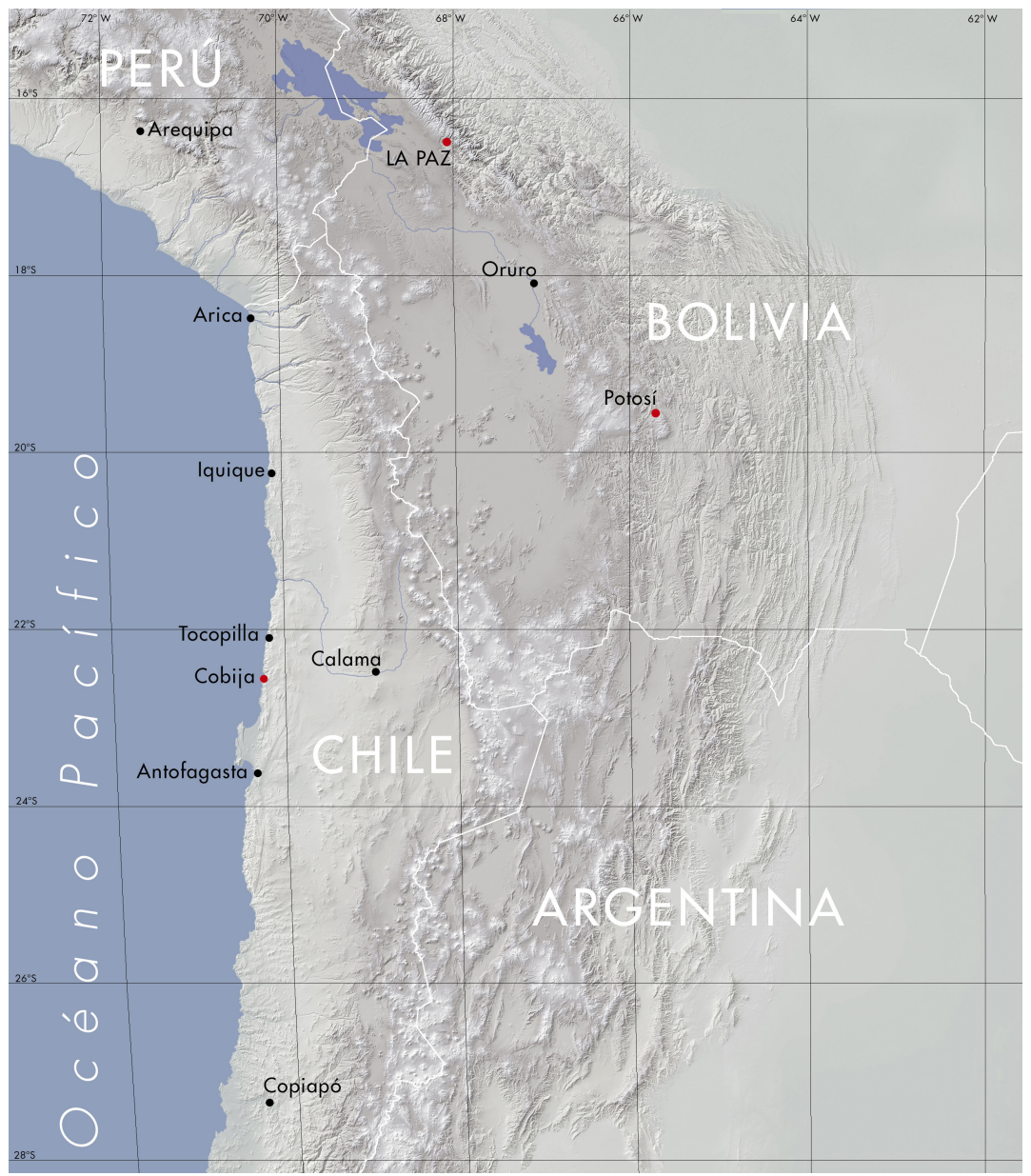

Figura 3. Mapa actual de la zona de estudio (Gentileza Fernando Maldonado). Current map of area of study (Courtesy Fernando Maldonado). 
fue incentivar el poblamiento de la zona. Dentro de las primeras, destacó la presencia real del Estado a través de la llegada del administrador de aduanas Horacio Álvarez y el establecimiento de una tasa de impuesto para las embarcaciones, bastante minoritaria en relación al resto de los puertos de la región(Cajías 1975; Téllezy Silva 2012).A esto se sumaron estrategias de incentivo migratorio a partir de exenciones tributarias y otorgamiento de tierras (Cajías 1975; Téllez y Silva 2012). Sin embargo, los esfuerzos más importantes para su crecimiento se dieron gracias a la llegada de Andrés de Santa Cruz a la presidencia de Bolivia, quien comprendió la situación de aislamiento en que el puerto y, consecuentemente, Bolivia se encontraba (Cajías 1975). Es en este contexto, que en 1832 Santa Cruz declaró el Puerto de Lamar completamente franco (Arce 1997 [1930]; Cajías 1975). Como señala Cajías: "para el fomento del Puerto, se había adoptado una política liberal por la cual el Estado renunciaba a toda intervención fiscal en relación a los buques que llegaban al Puerto y al comercio que se realizaba dentro de él" (Cajías 1975:239).

En 1831, el gobierno peruano amenazado por la posibilidad del establecimiento de la Confederación Perú Boliviana bloqueó el Puerto de Cobija y en 1835 fue completamente destruido a manos del peruano Santiago Salaverry (Cajías 1975; Godoy 2013), lo que constituyó un revés importante al desarrollo del puerto producto del éxodo masivo de la población posterior a estos eventos.

En 1837 se conformó la Confederación PerúBoliviana, bajo el mando del Mariscal Santa Cruz, la que tuvo una existencia de tres años. Durante este periodo se instaló una aduana boliviana en Arica, lo que produjo un desincentivo de Lamar, considerando que se sabía que Arica ofrecía mejores condiciones de conexión entre la costa y el interior que Cobija (Cajías 1997; Téllez y Silva 2012).

Posteriormente, se identifica un segundo momento correspondiente a un periodo de consolidación social y económica del puerto durante la década de 1840, gracias a la explotación del guano. Durante esta época, arribaron una gran cantidad de extranjeros entre los que destacaron peones chilenos-mestizos quienes compensaron la necesidad de mano de obra para el trabajo extractivo en las guaneras (Pinto y Valdivia 1997). De hecho, la presencia chilena fue tan importante que, para la creación de Antofagasta en 1879, dependiente del Departamento del Litoral de Cobija, la mayoría de su población era chilena (González 2004). Además, destacó la presencia de culíes (población china), pero en una cifra muy baja en relación a los presentes en las guaneras peruanas (Letelier y Castro 2016).

Desde 1842, cuando el Congreso chileno declaró la apropiación de territorio entre Copiapó y Mejillones (AGH, Vol. 1, 1842), hasta el tratado de 1866 entre Bolivia y Chile, se desató una disputa por la pertenencia del Puerto de Mejillones, área muy relevante para la extracción del guano y que junto con las disputas posteriores relacionadas con la extracción del salitre tuvieron como corolario la Guerra del Pacífico.

Finalmente, una tercera fase se identifica a partir de la década de 1870 , periodo que se inauguró con el descubrimiento del mineral de plata de Caracoles y el comienzo incipiente de la industria salitrera. A partir del desarrollo de la minería de la plata, se habilitó la caleta de La Chimba, en Antofagasta, perdiendo el monopolio el Puerto Lamar (Pérez 1997). Este período fue el de mayor decadencia para Cobija, lo que se reflejó en una notable disminución poblacional en desmedro del crecimiento de Mejillones, Antofagasta y Caracoles y que tuvo como consecuencia prácticamente el abandono total del puerto posterior al maremoto de 1877.

\section{Los Viajeros}

Los motivos de los viajeros durante el siglo XIX para llegar a América del sur fueron variados, siendo uno de los más importantes la búsqueda de lugares para expandir los avances tecnológicos asociados a la industria, que anunciaban la segunda revolución industrial (Pratt 2000). Este objetivo se convirtió en el prisma a través del cual los espacios geográficos comenzaron a ser vistos.

La llegada de estos viajeros y sus escritos, tantos científicos como experienciales, generaron el nuevo mapa de la expansión capitalista mercantil, que marcaron hasta el día de hoy los ejes de poder mundial. Estos nuevos mundos por explorar y explotar fueron categorizados a través de un relato que constituye una fuente limitada, pero de gran riqueza para conocer parte de los contextos locales.

Para el caso de Cobija, durante el siglo XIX arribaron varios personajes dentro de los que destacaron los franceses Jacques Antoine Moorenhout y William Bollaert, ambos en 1828 y Alcides D’Órbigny, en 1830. A ellos se suman otros viajeros naturalistas de diversas nacionalidades como Rodolfo Philippi, alemán, quien viajó a Cobija entre 1853-1854 y Johan J. Von Tschudi, austriaco, quien estuvo en el puerto en 1858 (Castro et al. 2012; González 1992; Letelier y Castro 2016).

Tomando algunos ejemplos particulares destacamos al naturalista Alcides D' Orbigny, quien en una de sus expediciones descritas en su libro "Viaje a la América Meridional", realizada entre 1826 y 1833, narró el paso por los principales puertos de la costa Pacífica abarcando desde Chile a Perú (D’Orbigny, 1835). Ante los ojos de D' Orbigny al llegar a Cobija percibió un desierto árido y sin vida:

Si el perfume de las flores y el aspecto grandioso de la vegetación del Brasil exaltó mi espíritu a 
mi llegada a Río de Janeiro, estuve muy lejos de experimentar las mismas emociones al recorrer con los ojos la campaña de Cobija. Me sentí por el contrario, profundamente entristecido (D’Orbigny 1835:933).

Pese a los sentimientos de D'Orbigny hacia Cobija, dentro de sus escritos destaca la presencia del guano sobre los puntos rocosos, recurso orgánico que fue usado como fertilizante y que se convirtió en uno de los recursos extractivos más importantes de la zona durante la década de 1840 (D’Orbigny 1835).

Otro caso interesante fue el del norteamericano William Ruschenberger, cirujano, oriundo de Nueva Jersey, que llegó en 1832 a Cobija con tan solo 25 años (Lofstrom 1991). La perspectiva del norteamericano sobre Cobija no fue alentadora, señalando que quienes habitaron el puerto poseían una vida dura y sacrificada (Ruschenberger 1935). Sin embargo, como señaló este mismo visitante: "El instinto o la experiencia enseñan que aquí no hay nada que pueda atraer al ser humano o al animal; y sin embargo ¡Qué no sacrifica el hombre para obtener el oro!" (Lofstrom 1991:62).

Cobija se convirtió a ojos extranjeros en un paisaje contradictorio, por un lado, el desierto desolado, carente y deshabitado, pero por otro, un espacio rico de recursos por explotar y, por lo tanto, un escenario lleno de oportunidades para el que era necesario generar un sistema de explotación efectiva de sus recursos (Pratt 2000).

\section{Indígenas}

La presencia de los pueblos indígenas durante el periodo Colonial en Atacama es bastante extensa. A fines del siglo XVIII había cerca de 2.936 indios en Atacama la Alta y 721 en la Baja (Cañete y Domínguez 1974 [1791]). En tanto, en 1804 se consignó 398 contribuyentes en Atacama la Alta y 106 en La Baja (Cajías 1975). No obstante, para principios del periodo republicano estas cifras fueron menores. Las razones son varias. En el caso de la costa, se asocia al fuerte contacto e intercambio con poblaciones foráneas y a la invisibilización en la documentación de la población cazadora recolectora costera debido a sus hábitos de movilidad.

Con respecto a las políticas republicanas, una de las primeras medidas tomadas por Bolívar en octubre de 1825 fue la abolición del tributo indígena, reemplazándolo por una contribución general que debía pagar todo hombre entre 18 y 60 años. Esta disposición dejaba atrás distinciones del periodo Colonial, pero lamentablemente, no esclarecía aspectos sobre la tenencia de la tierra. Sin embargo, esto solo duró un año, ya que en septiembre de 1827 se declaró la revocación de la medida tomada por Bolívar (Irurozqui
1999). En ese sentido, los distintos pueblos indígenas en Bolivia se vieron obligados a mantener al Estado a través del tributo, considerando que más de la mitad de las finanzas estatales fueron obtenidas por este medio. La justificación de este sistema, consistía en que el Estado reconocía la propiedad de la tierra a los indígenas y en retorno, ellos cancelaban el tributo (Cajías 1975). Bajo este parámetro, es que desde inicios de la República boliviana se establecieron diferencias no solo culturales, sino que también legales en torno al trabajo indígena y la obtención de tierra.

Dentro de los pueblos más importantes en la zona destacaron los Atacameños, quienes se habrían integrado desde momentos coloniales a la labor del arrieraje, transportando los productos desde y hacia Cobija (Aldunate et al. 2010), además de su labor en el servicio de posta y postillón (Choque 1997). El arrieraje, como una de las principales actividades desarrolladas por los indígenas en Atacama fue una herramienta para la obtención de circulante, necesario para la paga de tributos y costes de las economías comunitarias locales (Morales 2009).

Por otra parte, los grupos indígenas transitaron y constituyeron parte del paisaje sobre las bases de una tradición de integración ambiental previa (Letelier 2016). En ese sentido, la tradición arriera en Atacama, tan relevante para el desarrollo de la comunicación entre tierras altas y costa, fue más fuerte en los grupos alteños, con llegadas regulares a Cobija, pero sin residencias en el puerto (Letelier 2016; Letelier y Castro 2016). Asimismo, en el Censo de toda la provincia de Atacama en 1840 se señala que en "S. Pedro de Atacama produce bastante trigo, muchos alfares de los q se mantienen las recuas de Mulas, y Burros; los habitantes en lo jeneral arrieros, y labradores" (ANB MI, T80, $\mathrm{N}^{\circ} 25,1840$ ). Lo anterior se condice con los relatos de Philippi (1860) quien mientras se encontraba en la zona; pese a encontrarse en la costa, contrata a Atacameños con sus mulas para hacer su viaje de exploración hacia el interior (Letelier y Castro 2016). La anterior situación se dio desde momentos coloniales (Sanhueza 1991) y podría relacionarse con una tradición de "movilidad prehispánica en donde la tendencia es que la población alteña baje y la población costera suba en menos ocasiones" (Letelier 2016:231).

Por tanto, los arrieros atacameños integraron la costa como un espacio complementario dentro de la lógica de manejo de los diversos pisos altitudinales. Esto, comprendiendo que "La percepción y el conocimiento que el hombre andino adquirió de sus múltiples ambientes naturales a través de milenios le permitió combinar tan increible variedad en un solo macrosistema económico" (Murra 2002:85).

No obstante, pese a que la percepción atacameña del paisaje estuvo cruzada por una tradición previa, 
el incentivo del capitalismo trajo transformaciones importantes gracias al desarrollo de nuevos núcleos comerciales a lo largo del espacio andino que modificaron la movilidad (Letelier 2016). En ese sentido, los núcleos mineros fueron fundamentales como es el caso de Potosí y el noroeste argentino, desde donde se obtenían las mulas (Sanhueza y Gunderman 2007). Por lo tanto,

aunque se sabe que el uso de Cobija es previo, su configuración como puerto oficial lo convirtió en un punto esencial para los arrieros atacameños, tanto para llevar la carga, principalmente, minera como para la obtención de productos extranjeros (Letelier 2016:232).

Por otra parte, los pueblos costeros changos fueron menos visibles desde la documentación en el ámbito relacionado con el trabajo, posiblemente por su mantención de modo de vida cazadorrecolector marino tradicional (Aldunate et al. 2010). Los Changos, que aparecen registrados en momentos republicanos iniciales, responden más bien a un conjunto de tradiciones previas desarrolladas por grupos cazadores-recolectores costeros.

Estos grupos, se movieron principalmente por la costa y mantuvieron patrones de asentamiento dispersos -junto a una organización social relativamente igualitaria y no centralizada-, constituyen una multiplicidad de entidades sociales que, posiblemente, se reconocieron como distintos entre sí, pero que, a su vez, contaban con elementos comunes que facilitaron su intercambio y parentesco. Por lo tanto, es factible reconocer una continuidad cultural, por lo menos a nivel de identidad productiva, de los grupos costeros desde momentos prehispánicos en adelante, como también su integración al sistema de poder político y económico republicano que, en la zona del Loa se expresó en la modificación de las actividades correspondientes a la integración en actividades portuarias como indios cargueros (D'Orbigny 1945) y un crecimiento explosivo de la actividad minera (Larraín 1994; Letelier 2011). Esto último lo observó Rodolfo Philippi, a mediados del siglo XIX, quien señaló que un grupo de arrieros atacameños que buscaban la obtención de mariscos y pescado seco en la costa en Paposo a cambio de hojas de coca, vieron su negocio fracasado ya que

...Llegados a la costa hallaron, sin embargo, sus esperanzas en gran parte frustradas, porque la mayor parte de los changos, en vez de dedicarse a la pesca, habían preferido trabajar en las minas; los atacameños, pues habían podido comprar solamente una cantidad pequeña de pescado (Philippi 1860:60).
Los changos, habrían tenido una percepción del paisaje sin distinción de los límites de las recientes naciones. Esto, comprendiendo que, aunque tenían conocimiento sobre qué territorio pertenecía a Bolivia y a Chile, estos espacios, a través del mar eran transitados permanentemente. De hecho, una de las cosas que a D' Orbigny (1835) llamó la atención fue que el pescado fresco no se traía de la costa inmediata de Cobija, sino de Copiapó, emplazado a más de un centenar de kilómetros al sur del puerto, correspondiente a territorio chileno.

Las características más notables de los pescadores de Atacama fue su vínculo con el mar, tanto en relación a la subsistencia como del desarrollo de tecnologías vinculadas a la explotación de este (Llagostera 1982). Dicho vínculo se mantuvo durante la República y pese a modificarse a la luz del incentivo del capitalismo en clave mercantil y de la llegada y modificación de las tecnologías existentes, siguió relacionándose con el mar y su entorno.

\section{Empresarios y Comerciantes}

Desde el nacimiento de Lamar, el gobierno boliviano dio una serie de beneficios para dar impulso al desarrollo del puerto comprendiendo que Cobija no ofrecía las condiciones ideales principalmente por la falta de agua y problemas de conectividad hacia el interior (Cajías 1975). En este contexto, el rol de los empresarios y comerciantes, sobre todo en concordancia con la elite gobernante boliviana fue fundamental. Pese a los desacuerdos de las casas comerciales con las políticas económicas de Bolivia, sobre todo la primera mitad del siglo XIX, estas disfrutaron de ciertos privilegios como concesión de minas a particulares y la libre exportación (Cajías 1975; Letelier 2016). Esto, debido a que los empresarios eran parte fundamental del proyecto de estado nación ya que permitían la conexión con el resto del mundo y, además, eran quienes lo financiaban con el desarrollo del comercio local y a través de empréstitos al gobierno boliviano tanto para cuestiones vinculadas con el puerto como de otros asuntos del Estado. En ese sentido, la necesidad de inversión habría aflojado un control efectivo de aspectos como el contrabando por parte de las autoridades, contrabando en el que los diversos empresarios se vieron envueltos.

A grosso modo, las casas comerciales desarrollaron dos vertientes de negocios: en primer lugar, los productos extractivos, los cuales era exportados casi en su totalidad (destacando el cobre y el guano), ambas producciones de carácter secundario en relación a otros asentamientos ${ }^{2}$. En segundo lugar, los productos extranjeros de consumo que eran internados por Cobija. La primera vertiente guarda relación con la idea 
de una política económica extractiva del Estado nación boliviano, que se reflejó claramente en Cobija, pese a que el objetivo primario del puerto constituía el tema de la conexión ultramarina. Sin embargo, a medida que avanzó el tiempo, la preocupación por los recursos minerales y orgánicos que ofrecía Atacama fueron tomando mayor relevancia, relegando a segundo plano la conexión ultramarina para importación de productos, la cual siempre fue mucho más expedita por Arica.

Uno de los primeros empresarios que se asentó en Cobija fue el español Lucas de la Cotera, proveniente de Arequipa (Condori 2011). En marzo de 1827, Sucre autorizó a de la Cotera la instalación de un puesto comercial en el puerto y de exploraciones de ruta hacia el interior (Condori 2011) En este contexto, destacan las palabras de Atanasio Hernández, en su observación efectuada en mayo de 1830 al Gobierno de Bolivia, en donde señaló lo siguiente:

Esta naciente población debe su primer establecimiento al español Lucas de la Cotera, quien á costa de sacrificios pecuniarios y la protección del Gobierno pudo situar las primeras habitaciones, y abrir la comunicación al interior por medio del reparto y habilitación de mulas Atrajo pobladores que despues hán continuado adelantando la construccion de Casa a medida que el Puerto se ha conocido y frecuentado. La mayor parte de estos nuevos pobladores fueron europeos los cuales abrazando con ardor la empresa de situarse, hán trabajado en todos los ramos, y ellos es que, vá saliendo de la nada un Pueblo mercantil con las formas de una sociedad regular. Algunos habitantes de uno y otro sexo Americanos se hán avecindado posteriormente, mas á escepcion de los empleado, ninguno es Boliviano. Puede formarse concepto de los individuos de que se compone esta Colonia, sabiendo que hay de todos los Estados vecinos, y Europeos, menos hijos, ni familias del País (ANB MI, Tomo 31, N²2, 1830).

Otro empresario importante en Cobija fue don José María Artola, comerciante español, que posteriormente formó la sociedad Artola Hermanos, firma de gran éxito en la zona (Arce 1997 [1930]). Dentro de sus negocios destacaron agencias comerciales tanto en Cobija como en Calama; la explotación, compra y venta de metales e incluso se lo ha vinculado con la trata de culíes (Segall 1968).

A los empresarios españoles se suma la presencia de los franceses Domingo y Máximo Latrille, Ramón y Amán Lemaitre, Juan y Pedro Garday; y el chileno José Santos Ossa, entre otros (Arce 1997 [1930]), destacando una población de carácter multinacional
(Galaz-Mandakovic y Owen 2015). Este grupo, en su mayoría llegó a probar suerte, con escasos recursos, pero aprovecharon las condiciones de privilegio que tenían al ser europeos, en esta dinámica neocolonial. De este modo, destacó el desarrollo una creciente industria de carácter extractiva, en principio fuertemente vinculada a la explotación del cobre, en la que posteriormente, tomó mayor protagonismo el guano y hacia la década de 1870 , la plata y el salitre.

Los empresarios del puerto, dispusieron de reconocida libertad por parte de las autoridades administrativas del puerto para el desarrollo de sus negocios constituyéndose Cobija y Atacama como la tierra de las oportunidades. Además, establecieron una red de parentesco que permitió afianzar el desarrollo de los negocios locales, más allá del límite de las nacionalidades y los territorios de cada país. Así, por ejemplo, José Santos Ossa se casó con una hija de José María Artola, y la hija de ambos con Andrés Garland, importante empresario de la zona.

Para este grupo, su percepción del paisaje se vislumbró como un desierto salvaje y despoblado repleto de recursos naturales, delimitados en función de la propiedad privada. Acá, Cobija emerge como la utopía urbana, en medio de la aridez, cuya historia de progreso se delimitó en función de los recursos asociados y el esfuerzo personal. En ese sentido, los empresarios, pese a tener privilegios, se sintieron abandonados por el Estado, aflorando la sensación de la promesa incumplida sobre la oportunidad comercial de asentarse en Cobija, situación que expresa don Manuel Solá, empresario de origen argentino, al prefecto de Cobija a nombre de la junta de vecinos del puerto el 30 de junio de 1845 .

[...] a 21 años de la creación de este puerto poco y nada parece que le hubiera costado los desvelos del Gobierno, por que no ofrece un solo monumento, una obra pública de importancia, ni cosa en que aparezca marcada la mano de la autoridad del Estado. A esepcion de las fuentes de agua, y los almacenes que se trabajan e la actualidad, lo demas que háy en Cobija és esclusivamente debido a los esfuerzos de sus habitantes y á los beneficios que deja siempre el comercio, aunque no sea mas que de tránsito (ANB MI, Tomo 109, No 37, 1845).

\section{Peones y Culíes}

El cuarto escenario sobre el que nos situamos hace referencia al peonaje, parte fundamental del desarrollo de la minería del actual Norte Grande. Este se sustentó en una masa de trabajadores, primordialmente población mestiza, proveniente mayoritariamente 
desde Chile (Letelier y Castro 2016), muchos de ellos del norte semiárido.

Con la creación de Lamar, se generaron políticas de poblamiento específicas para indígenas, aunque, las condiciones de Cobija y la contribución indígena dificultaron la permanencia de esta (Letelier y Castro 2016; Pinto y Valdivia 1997). De este modo, se incentivó el desplazamiento de trabajadores asalariados provenientes desde Chile, fundamentalmente a partir de la década de 1840 para el trabajo en las covaderas (Letelier y Castro 2016; Pinto y Valdivia 1997) y estalló, posteriormente, con el descubrimiento del mineral de Caracoles en 1870, periodo en que aumentó ostensiblemente el número de habitantes en Cobija pero, sobre todo, sus alrededores (Aldunate et al. 2008; Cajías 1975).

Como plantea Salazar (1985) "el peón del siglo XIX era el heredero directo del "antiguo" vagabundo colonial" (Salazar 1985:148-149), y su origen se arraigó en la crisis del campesinado criollo a fines del siglo XVIII (Salazar 1985). Estos peones-gañanes mestizos, representaron trabajadores de segundo orden, es decir, mano de obra no especializada que detentaban "todos los oficios forzados y salariales- no campesinos, pero pre proletarios" (Salazar 1985:156) y, por tanto, poseían una situación laboral precaria.

La presencia de peones chilenos fue altamente conflictiva tanto para la población local de Cobija como de los intereses económicos del Estado boliviano. En ese contexto destacan las palabras del gobernador de Cobija Gaspar Aramayo al Ministro de Hacienda de Bolivia en donde señala que los trabajadores chilenos eran "Insolentes por carácter y ebrios casi siempre por costumbre" (ANB MH, Tomo 19, No 31, 1848).

Asimismo, esta población se caracterizó por su itinerancia. De hecho, algunos peones llegaron a lugares tan lejanos como California, motivados por la fiebre del oro a mediados del siglo XIX (Letelier y Castro 2016).

El tránsito desde Chile a las costas bolivianas fue permanente, de modo que la zona de Atacama fue concebida como un espacio de tránsito temporal con recursos laborales abundantes y donde el trabajo era duro. En este escenario, surgen las relaciones sociales entre los trabajadores, en su mayoría migrantes, y la relación de estos con el desierto, proceso que generó una masa laboral "a medio camino entre su origen campesino y su destino proletario-industrial" (Salazar 1985:152) debido a su deficiente formación para ejecutar tareas específicas (Salazar 1985).

Por otra parte, se debe mencionar a la población china denominada culíes. La trata de culíes se inició motivada por el contexto social, político y económico de China hacia la década de 1840 debido al desfalco del opio e inflación económica. Esto, generó una migración masiva de la población rural a las ciudades $\mathrm{y}$, consecuentemente, la disponibilidad de mano de obra de bajo costo. Los ingleses fueron los primeros en aprovechar esta situación, cuestión que posteriormente se masificó (Hincapié 2001).

La forma por la cual los culíes eran llevados a tierras lejanas era a través de contratos engañosos, de esa forma adquirían una deuda por la cual debían pagar con una vida de trabajo en condiciones infrahumanas (Segall 1968). Para el caso particular de la zona de estudio, entre 1845 a 1875 llegaron a Perú cerca de 100.000 culíes quienes trabajaron principalmente en la extracción del guano (Hincapié 2001). En tanto, para Bolivia y Chile la presencia de población proveniente de china fue bastante menor (Segall 1968).

En Cobija, hay un exiguo registro de culíes, sin embargo, gracias a los trabajos de Segall (1968) se plantea que la casa Artola estuvo vinculada con su tráfico. Así, para los culíes Cobija y la costa de Atacama se transformó en una condena, el mar y el desierto fueron el escenario de una vida de trabajo sin recompensa. Durante la Guerra del Pacífico, muchos de los chinos prestaron importantes aportes al ejército chileno; esta guerra, convirtió a estos esclavos en trabajadores libres para el salitre, en fecha posterior a 1885 (Lin Chou 2004).

\section{Palabras Finales}

La imagen de las ruinas actuales de Cobija son los cimientos de un espacio material, cuya historia local aún se esconde entre los adobes. Esta historia es la del desarrollo de un proyecto político, que tuvo como resultado la conformación de un puerto cosmopolita de donde se desprenden diversos relatos, imaginarios y paisajes y cuya historia se vio truncada por el contexto político y económico.

No obstante, el proyecto político, más allá de constituirse en la salida al mar de Bolivia, fue el eje desde donde se articularon diversas realidades integradas por elementos del capitalismo, del colonialismo y de los aspectos tradicionales de las sociedades precolombinas en un escenario único, el desierto, entendiéndolo como un elemento activo dentro del entramado sociocultural. Así el proyecto político se enmarcó en la contradicción entre éste y la convergencia de diversos actores sociales como bolivianos, extranjeros, indígenas, entre otros, quienes dieron vida al puerto y que tuvo su golpe de gracia con el maremoto de 1877.

En este caso particular, los procesos sociales locales se estructuraron a partir de un eje mayor de relaciones sociopolíticas y culturales vinculado a los EstadosNaciones en el espacio latinoamericano y su disposición a partir del sistema-mundo (Wallerstein 2003). Es en esta disposición donde las élites cumplieron un rol fundamental, ya que son estas las que se insertaron en 
el sistema a través de la apropiación de ideas europeas y del desarrollo del comercio internacional (Carmagnani 2004). Todo esto manejado por una oligarquía de origen principalmente europeo, cuyo poder se sustentó en el control económico de la producción de Atacama.

De este modo, en Atacama se dio un proceso de transformación identitaria en donde la intensificación de la industria extractiva, en contexto del desarrollo del capitalismo industrial a nivel mundial, vinculado al aumento de la producción y circulación de productos, fueron de gran importancia en la transformación de la percepción del paisaje.

En ese sentido, los diversos grupos sociales que convivieron en el puerto poseían distintas formas de aprehender este espacio, las que fueron transformándose a través del tiempo en el marco del desarrollo de una sociedad minera preindustrial en donde los distintos grupos se convirtieron en agentes activos de este proyecto socioeconómico. Sin embargo, se entiende que los diversos imaginarios se erigieron como conflictivos y en constante roce, cruzados por aspectos étnicos, ideológicos y económicos. Así, la forma de percibir el desierto, el mar y sus recursos, tanto ideológicos como económicos, fueron diversos y dinámicos.

Agradecimientos: A los proyectos de investigación FONDECYT N ${ }^{\circ}$ 1100951, Anillo SOC 1109, Anillo SOC 1405. A los investigadores Sergio González Miranda y Pablo Artaza Barrios. Al Archivo Nacional de Bolivia y al Archivo del Ministerio de Relaciones Exteriores de Chile. Agradecemos también a los revisores anónimos por sus valiosas sugerencias.

\section{Referencias Citadas}

Aldunate, C., V. Castro y V. Varela 2008. San Bartolo y Cobija: Testimonios de un modo de vida minero en las tierras altas y la costa de Atacama. Estudios Atacameños 35:97-118.

Aldunate, C., V. Castro y V. Varela 2010. Los Atacamas y el pescado de Cobija en homenaje al maestro John Víctor Murra Chungara Revista de Antropología Chilena 42 (1):341-347.

Arce, I. 1997 [1930]. Narraciones Históricas de Antofagasta. Autoedición, Fondo Nacional de Desarrollo Regional, I. Municipalidad de Antofagasta, Antofagasta.

Baeza, M.A. 2003. Imaginarios Sociales. Apuntes para la Discusión Teórica y Metodológica. Ediciones Universidad de Concepción, Concepción.

Bibar, J. de 1966 [1558]. Crónica y Relación Copiosa y Verdadera de los Reinos de Chile. Fondo Histórico y Bibliográfico José Toribio Medina, Santiago.

Bittmann, B. 1980. Proyecto de investigación interdisciplinaria en la Costa Centro-Sur Andina. En Proyecto de Investigación Interdisciplinaria en la Costa Centro-Sur Andina, editado por B. Bittmann, M.T. Ahumada y C. Moragas, Vol I, pp. 11- 20. Universidad del Norte, Imprenta Universitaria, Antofagasta.

Borie, C., V. Castro, V. Varela y C. Aldunate 2016. Cobija y sus vías de conexión con el interior de Atacama. Desde la Colonia hasta la guerra del Salitre. Diálogo Andino 49:209-223.

Bresson, A. 1886. Bolivia: Sept Années d'éxplorations de Voyages dans L'Amerique Australe. Challamel Ainé, París.

Cajías, F. 1975. La Provincia de Atacama. 1825-1842. Instituto Boliviano de Cultura, Empresa Editora Universo, La Paz.

Cajías, F. 1997. El norte y el sur de Bolivia: Arica y Cobija en los primeros años republicanos. En El Siglo XIX en Bolivia y América Latina, editado por R. Barragán, D. Cajías y S. Qayum, pp.129-137. IFEA, La Paz.

Cajías, F. 2007. La posesión de Atacama y la habilitación del puerto de Cobija, 1824-1845. En Del altiplano al Desierto. Construcción de Espacios y Gestación de un Conflicto, editado por E. Cavieres, pp. 83-136. Ediciones Universitarias de Valparaíso, Valparaíso.
Cañete y Domínguez, P. 1974 [1791]. Noticia Tercera: Del Puerto de Santa Magdalena de Cobija y su comarca, con algunas reflexiones importantes sobre si conviene o no fomentarlo de cuenta de la Real Hacienda. Revista Norte Grande 1 (1):82-97.

Carmagnani, M. 2004. El Otro Occidente. América Latina desde la Invasión Europea hasta la Globalización. Fondo de Cultura Económica, México D.F.

Castoriadis, C. 1997. El Imaginario social instituyente. Zona Erógena 35:1-9.

Castoriadis, C. 2005. Los Dominios del Hombre. Las Encrucijadas del Laberinto. Gedisa editorial, Barcelona.

Castro, V. 2009. De Idolos a Santos. Evangelización y Religión Andina en Los Andes del Sur. Fondo de Publicaciones Americanistas Universidad de Chile, Centro de Investigaciones Diego Barros Arana. Ediciones de la Dirección de Bibliotecas, Archivos y Museos, Santiago.

Castro, V., C. Aldunate y V. Varela 2012. Paisajes culturales de Cobija, costa de Antofagasta, Chile. Revista Chilena de Antropología 26:97-128.

Castro, V., C. Aldunate,V. Varela, L. Olguín, P. Andrade, F. GarcíaAlbarido, F. Rubio, P. Castro, A. Maldonado y J. Ruz 2016. Ocupaciones Arcaicas y probables evidencias de navegación temprana en la costa arreica de Antofagasta, Chile. Chungara Revista de Antropología Chilena 48 (4):503-530.

Cavieres, E. 2007. La construcción de los espacios: significaciones económicas y conflictos nacionales: Bolivia, Chile y Perú. 17801840. En Del Altiplano al Desierto. Construcción de Espacios y Gestación del Conflicto, editado por E. Cavieres, pp. 17-40. Ediciones Universitarias de Valparaíso, Valparaíso.

Choque, R. 1997. La servidumbre indígena andina de Bolivia. En El Siglo XIX. Bolivia y América Latina, editado por R. Barragán, D. Cajías y S. Qayum. IFEA, La Paz.

Claval, P. 2002. El enfoque cultural y las concepciones geográficas del espacio. Boletín de la Asociación de Geógrafos Españoles 34:21-39. 
Condori, J. 2011. Guerra y economía en Arequipa: las actividades del español Lucas de la Cotera en una coyuntura de crisis, 18211824. Revista de Indias LXXI (253):827-858.

D’Orbigny, A. 1835. Viaje a la América Meridional. Tomo III. Editorial Futuro, Buenos Aires.

Escobar, M. 2015. Para vivir en Cobija: prevalencia del modo de vida costero en Atacama. Chungara Revista de Antropología Chilena 47 (2):303-318.

Fifer, J.V. 1976. Bolivia. Editorial Francisco de Aguirre, S. A. Buenos Aires.

Galaz-Mandakovic, D. y E. Owen 2015. Hermanos Latrille: Impronta en el Desierto. Retruécanos Ediciones, Tocopilla.

Gallastegui, J. y J. Galea 2009. Espacios para una Geografía Social, Humanista y Crítica. Universidad de Playa Ancha, Valparaíso.

Godoy, M. 2013. Donde el cóndor de los Andes apenas se posa tímido. El puerto de Cobija y el litoral de Atacama en el informe del coronel Quintín Quevedo, julio de 1867. Estudios Atacameños 46:127-144.

González, J. 1992. La Comisión Científica Española al Pacífico en Chile (1862-1865). Diario de Francisco Martínez y Sáez. Ediciones Universitarias, Universidad Católica del Norte, Antofagasta.

González, S. 2004. La tercería boliviana y el problema de la mediterraneidad. Revista de las Fuerzas Armadas 18 (1-2):23-36.

Hincapié, L. 2011. Rutas del Pacífico: inmigrantes asiáticos a América Latina. En Memorias del XIII Congreso Internacional de la Asociación Latinoamericana de Estudios de Asia y África (ALADAA), Bogotá, pp.1-13. https://ceaa.colmex.mx/aladaa/ memoria_xiii_congreso_internacional/images/hincapie.pdf

Irurozqui, M. 1999. La paradojas de la tributación. Ciudadanía y política estatal indígena en Bolivia 1825-1900. Revista de Indias LIX (217):705-740.

Letelier, J. 2016. Entre la costa de Cobija y tierras altas: el tráfico arriero a inicios de la república boliviana. Diálogo Andino 49:225-234.

Letelier, J. y V. Castro 2015. Puerto de Cobija Lamar. La inserción de Bolivia al capitalismo entre 1825 y 1843. Actas del XIX Congreso Nacional de Arqueología Chilena, pp. 412-415, Arica.

Letelier, J. y V. Castro 2016. El Puerto de Cobija y la migración peonal. Transformaciones a inicios de la Republica. En Del hito a la Apacheta Bolivia - Chile: Otra Lectura de Cien Años de Historia Transfronteriza (1904-2004), editado por S. González, C. Ovando e I. Breton, pp. 455478. RIL editores, Santiago.

Lin Chou, D. 2004. Chile, De culíes a profesionales. En Cuando Oriente Llegó a América: Contribuciones de Inmigrantes, Chinos, Japoneses y Coreanos, pp. 35-52. Banco Interamericano de Desarrollo, Washington D.C.

Lindon, A. 2007. Diálogo con Néstor García Canclini ¿qué son los imaginarios y cómo actúan en la ciudad? EURE 33 (99):89-99.

Lizarraga, R. de 1987 [1594-1608]. Descripción del Perú, Tucumán, Río de la Plata y Chile. Ediciones de Ignacio Ballesteros, Historia 16, Madrid.

Lofstrom, W. 1991. Cobija y el Litoral Boliviano Visto por Ojos Extranjeros 1825-1880. Editorial Quipus, La Paz.

Llagostera, A. 1982. Tres dimensiones en la conquista prehistórica de mar. Un aporte para el estudio de las formaciones pescadoras de la costa sur andina. Actas del VIII Congreso de Arqueología Chilena, pp. 217-245. Editorial Kultrún, Santiago.

Márquez, F. 2007. Imaginarios urbanos en el Gran Santiago: huellas de una metamorfosis. EURE 33 (99):79-88.

Mitre, A. 1981. Los Patriarcas de La Plata. Estructuras Socieconómicas de la Minería Boliviana. Instituto de Estudios Peruanos IEP, Lima.

Morales, H. 2009. Etnopolítica en Atacama Laberintos de la Etnicidad Atacameña en Chile. Tesis doctoral. Universidad Libre de Berlín, Berlín.

Murra, J. 2002. El control vertical de un máximo de pisos ecológicos en la economía de las sociedades andinas. En El Mundo Andino. Población, Medio Ambiente y Economía, editado por J. Murra, pp. 85-125. IEP, Lima.

Pérez, H. 2001. América Latina en la transición demográfica, 18001980. Población y Salud en Mesoamérica, vol. 7, $\mathrm{n}^{\circ}$. 2. Sección de Documentos Históricos. Centro Centroamericano de Población, Universidad de Costa Rica, San José. Recuperado de: http://ccp.ucr.ac.cr

Philippi, R. 1860. Viage al Desierto de Atacama. Librería de Eduardo Antón, Halle.

Pinto, J. y V. Valdivia 1997. Peones chilenos en tierras bolivianas. En El Siglo XIX. Bolivia y América Latina, editado por R. Barragán, D. Cajías y S. Qayum, pp. 179-202. IFEA, La Paz.

Pratt, M. 2000. Ojos Imperiales. Literatura de Viajey Transculturación. Fondo de Cultura Económica, México D.F.

Randazzo, F. 2012. Los imaginarios sociales como herramientas. Imagonautas 2 (2):77-96.

Ruschenberger, W. 1935. Three Years in the Pacific; Containing Notices of Brazil, Chile, Bolivia, Perú 1831, 1832, 1833, 1834. Vol. I. Editorial Richard Bently, London.

Salazar, G. 1985. Labradores, Peones y Proletarios. Formación y Crisis de la Sociedad Popular Chilena del Siglo XIX. Ediciones Sur, Santiago.

Sanhueza, C. 1991. Orígenes y Desarrollo de la Arriería Indígena Colonial en Atacama Siglos XVI-XVIII. Tesis de grado de licenciatura. Pontificia Universidad Católica de Chile, Santiago.

Sanhueza, C. y H. Gundermann 2007. Estado, expansión capitalista y sujetos sociales en Atacama (1879-1928). Estudios Atacameños 34:113-136.

Segall, M. 1968. Esclavitud y tráfico. Culies en Chile. Journal of Inter-American Studies 10 (1):117-133.

Tellez, E. y O. Silva 2012. Noticias sobre los inicios históricos de Lamar (Cobija), primer puerto de Bolivia en el Pacífico (1828). Cuadernos de Historia 37:241-248.

Wallerstein, I. 2003. El Capitalismo Histórico. Siglo XXI Editores, México D.F.

Zusman, P. 2013. La geografía histórica, la imaginación y los imaginarios geográficos. Revista de Geografia Norte Grande 54:51-66.

\section{Fuentes primarias}

Archivo General Histórico, Ministerio de Relaciones Exteriores de Chile (AGH), Fondo Bolivia.

Archivo Nacional de Bolivia (ANB MH), Ministerio de Hacienda. Archivo Nacional de Bolivia (ANB MI), Ministerio del Interior. 


\section{Notas}

${ }^{1}$ El concepto de imaginario y su extensión, ha sido ampliamente discutido; véase por ejemplo Baeza (2003); Lindon (2007) entrevistando a García Canclini; Randazzo (2012), entre otros, y ampliamente descrito por Castoriadis, prácticamente el padre de este concepto (Castoriadis 2005). Nosotros nos hemos aproximado a esta noción, por su sintonía con el concepto de paisaje que venimos usando (Castro et al. 2006).

2 Es importante aclarar que la minería boliviana de la primera mitad del siglo XIX en Atacama fue bastante dispersa. Este panorama se mantuvo hasta avanzado el siglo XIX con el surgimiento de grandes centros mineros como Caracoles. En ese sentido, Cobija se constituyó en un centro minero secundario, en donde la labor fue más bien de pirquineo. Pese a su rol secundario, destacan intervenciones del Estado para el desarrollo de la minería local como la invitación del facultativo Miguel Fuentes en 1830 para efectuar exploraciones con el objetivo de "dar un fomento mas activo y eficaz al descubrimiento de las minas de cobre, plata, y oro, que se encuentran en la cadena de montañas que cruzan estas playas desde la punta de Gatico hasta la Bahia de Mejillones" (ANB MI, Tomo 21 Nº17, 1830). 